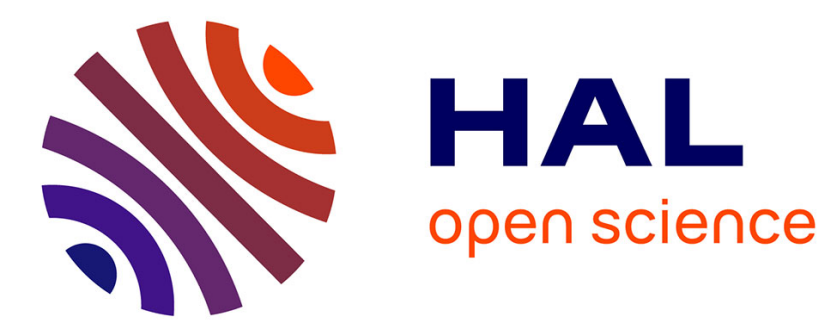

\title{
Void closure criteria for hot metal forming: A review
} Michel Saby, Pierre-Olivier Bouchard, Marc Bernacki

\section{To cite this version:}

Michel Saby, Pierre-Olivier Bouchard, Marc Bernacki. Void closure criteria for hot metal forming: A review. Journal of Manufacturing Processes, 2015, 19, pp.239-250. 10.1016/j.jmapro.2014.05.006 . hal-01022635

\section{HAL Id: hal-01022635 \\ https://hal-mines-paristech.archives-ouvertes.fr/hal-01022635}

Submitted on 11 Sep 2018

HAL is a multi-disciplinary open access archive for the deposit and dissemination of scientific research documents, whether they are published or not. The documents may come from teaching and research institutions in France or abroad, or from public or private research centers.
L'archive ouverte pluridisciplinaire HAL, est destinée au dépôt et à la diffusion de documents scientifiques de niveau recherche, publiés ou non, émanant des établissements d'enseignement et de recherche français ou étrangers, des laboratoires publics ou privés. 


\title{
Void closure criteria for hot metal forming: a review
}

\author{
M. Saby ${ }^{\mathrm{a}}$, P.-O. Bouchard ${ }^{\mathrm{a}}$, M. Bernacki ${ }^{\mathrm{a}}$ \\ ${ }^{a}$ Mines Paris Tech, CEMEF - Centre de Mise en Forme des Matériaux, CNRS UMR 7635 CS 102071 rue Claude Daunesse, \\ 06904 Sophia Antipolis cedex, France
}

\begin{abstract}
Void elimination through mechanical closure remains of prime importance for industrial applications. This paper presents a critical review on a large number of studies dealing with void closure in hot metal forming processes. In the literature, two main approaches were identified at two different scales: a macroscopic approach at the process scale and a micro-analytical approach at the void scale. Using the macroscopic approach, entire processes are generally considered with workpieces containing one or several voids, dealing with hot forging, hot rolling and related processes. Qualitative results, as well as empirical criteria and empirical prediction models are presented and discussed in this paper. Using the micro-analytical approach, an isolated void in an infinite matrix is considered and its evolution is analytically predicted. Analytical and semi-analytical prediction models involve a certain number of assumptions that are discussed in an industrial context. This paper presents a comparison between seven prediction models, in terms of void volume evolution under conditions that are typical for industrial applications. Stress triaxiality ratios are over the range $[-1.2,0]$ and several material behaviours are considered. Empirical models are hardly generalizable, as they are based on particular case studies involving one given void state or one given process. On the other hand, analytical and semi-analytical models suffer from strong assumptions. Consequently, their use in an industrial context remains limited. The use of a meso-scale approach is shown as a potentially powerful approach, as it may take advantage of both existing approaches from literature.
\end{abstract}

Keywords: void closure, hot metal forming, prediction model, criterion

\section{Introduction}

Industrial needs for large metal components for aerospace, transport, or energy applications constantly increase. After casting, the presence of internal voids may be observed in large ingots or preforms. Such internal defects must obviously be eliminated before delivery, as they may significantly affect the mechanical properties of final products. Void elimination is classically performed during the first steps of elaboration, involving hot metal processes (e.g. hot forging or hot rolling). This paper presents a review of various criteria and models that may be used to predict void closure in an industrial context.

Void closure generally involves two stages: the mechanical closure of the void (reducing the void volume to zero), and the final bonding of internal surfaces providing complete healing and thus a sound material [1]. The present work focuses on the first stage only: the mechanical closure.

Two different approaches are presented in literature regarding the mechanical closure phenomenon: an explicit macroscopic approach and a micro-analytical approach. The explicit macroscopic approach consists in studying a whole process with a workpiece in which voids are explicitly defined. The influence of various parameters on void closure is studied using experimental data [2, 3] or finite element (FE) simulations [4-9]. Criteria and prediction models are presented in a first section, as well as a discussion regarding their benefits and limitations.

Email address: michel.saby@mines-paristech.fr +33493957415 (M. Saby) 
The micro-analytical approach considers a single void in an infinite matrix [10-13]. The void volume evolution is analytically predicted, according to a certain number of assumptions. A review of these analytical prediction models is presented in a second section, and the assumptions are discussed. Gurson-based models [14] are also mentionned. Such models were initially developed for predicting the global behaviour of porous materials and were dedicated to ductile fracture (void growth under positive stress triaxiality ratios). However, interesting features were found out regarding void evolution and are compared to the approaches regarding void closure.

It is worth noticing that, although prediction models for void closure are generally based on a similar analysis than the one used for studying void growth, the involved micromechanisms are different in both cases. Regarding void closure, the mechanical deformation is the main driving parameter leading to the reduction of voids volume, while in void growth analyses, voids coalescence and nucleation mechanisms must also be considered (see e.g. [15-19]). Such mechanisms are out of the scope of the present study, which focuses on mechanical closure of voids, only.

\section{Macroscopic approach}

Due to the great industrial interest in understanding void closure, numerous studies on void closure were conducted using the macroscopic explicit approach. This approach enables a process to be partially or fully described and the closure mechanisms to be studied in accurate process conditions. The influence of process parameters was studied in order to establish qualitative or quantitative relationships between the parameters and the void closure efficiency.

Main qualitative results are summarized first, with a brief description of the studies conditions (considered processes, types of voids). The two main families of processes that are typically concerned are hot forging and hot rolling. The main features dealing with void closure are summarized for each process family.

In a second part, existing prediction models are presented and discussed.

\subsection{General qualitative results}

The macroscopic explicit approach generally involves experimental testing or numerical simulation. From a general point of view, the following statements were found out:

i. large deformations, especially in the first stages of forming processes, are preferred for better void closure $[2-4,7,20-26]$;

ii. a relevant choice of process configuration may considerably improve the void closure efficiency: shapeddies for forging $[6,7,20,24,27-29]$ and large roll radius for rolling [3, 23, 25, 26, 30];

iii. temperature gradient in the workpiece also plays an important role and it is shown that a colder skin improves the closure of centerline voids [7, 26, 31-34];

iv. friction with dies may also improve the voids closure efficiency [4, 23].

The influence of strain-rate had not been studied regarding void closure evolution.

\subsubsection{Hot forging}

For open die forging and cogging processes, various conditions were tested and are briefly summarized in Table 1. Most studies considered steel in its typical working temperature $\left(900-1250^{\circ} \mathrm{C}\right)$. Aluminium, plasticine and lead $(\mathrm{Pb})$ were also used. Height reduction ratios varied between 10 and $40 \%$ per pass. In general, it was observed that larger values are preferred for a better closure. In the case of multi-pass forging, it was shown that the reduction of the first pass generally brings the main contribution to void closure, and that the contribution of following passes may become insignificant [24].

Överstam and Jarl [33] investigated the effects of natural cooling and the one due to the contact with the tools. Surface cooling generally had a positive effect on void closure. The study showed that the effect 
of temperature gradient is significant for small billets (size $<200 \mathrm{~mm} \times 200 \mathrm{~mm}$ ), but becomes negligible for large billets.

Different tool shapes were investigated: bowl-shape [7, 20], V-shape [5, 9], FML (Free of Mannesmann effect at Lower press load) [6], and BFTV (Bottom Flat Top V) [27]. Concave tools were shown to provide better void closure. The positive effect of concave dies, compared to flat dies, results from a more compressive stress triaxiality state at the billets center. This is coherent with the effect of temperature gradient (colder skin) mentioned previously, as both involve more compressive states at the core of workpieces.

Banaszek and Stefanik [7] studied the evolution of a billet's 2D-section containing circular voids during hot forging. They proposed a relation between the total surface area of defects and forging parameters (i.e. upper die speed, relative reduction and initial temperature). A statistical analysis on case studies was performed using FE simulations and several experimental validation cases. The authors concluded that void closure is enhanced when using asymmetrical concave dies in the early stages, and flat dies in the final stages of forging.

\subsubsection{Hot rolling}

For the studies regarding rolling processes, steel was mostly studied as well (see Table 2). The technical report Improsound [26] relates a large quantity of results regarding the optimization of multi-pass hot rolling. Several pass-schedules were studied. It was shown that a one-pass schedule brings better void closure than a two-pass schedule with identical cumulated reduction ratios. Further studies regarding multipass schedules confirmed that the effect of the first pass is predominant regarding void closure. Lower numbers of passes with large reductions, and without turning the billet between the passes, are thus recommended for better void closure. Wallerö [3] studied the effect of rolling conditions and concluded that passes involving large spread ratios are favourable for void closure.

\begin{tabular}{|c|c|c|c|c|c|c|c|}
\hline Source & Material & $\begin{array}{l}\text { Process, billet } \\
\text { dim. }(\mathrm{mm})\end{array}$ & $\mathrm{T}\left({ }^{\circ} \mathrm{C}\right)$ & $\begin{array}{l}\text { Reduc. }(\%) \\
\text { or eq. strain }\end{array}$ & $\begin{array}{c}\text { strain-rate } \\
\left(s^{-1}\right)\end{array}$ & Void shapes & $\begin{array}{c}\text { Void/billet } \\
\text { ratios }\end{array}$ \\
\hline [6] & $\begin{array}{c}\text { Steel, } \\
\text { plasticine }\end{array}$ & $\begin{array}{c}\text { Open die } \\
\varnothing 2800\end{array}$ & 1230 & $30 \%$ & 0.01 & 2D cylinder & 0.07 \\
\hline$[1,27]$ & Steel & $\begin{array}{l}\text { Open die } \\
\varnothing 100 \times \text { L80 }\end{array}$ & $1000-1200$ & 0.35 & 0.01 & Cylinder & 0.1 \\
\hline [29] & Steel & $\begin{array}{l}\text { Multipass } \\
300 \times 350\end{array}$ & $1043 \rightarrow 848$ & $40 \%$ & $0.1-0.2$ & $\begin{array}{l}\text { Sphere, } \\
\text { cylinder }\end{array}$ & 0.03 \\
\hline [33] & Steel & Open die & 1100 & - & - & - & - \\
\hline$[7]$ & Steel & $\begin{array}{l}\text { Open die } \\
\varnothing 80 \times \mathrm{L} 80\end{array}$ & $1100-1250$ & $0.15-0.25$ & $0.1-0.2$ & 2D cylinder & $0.05-0.12$ \\
\hline$[24]$ & Steel & Multipass & 1000 & $30 \%$ & - & - & - \\
\hline [35] & $\begin{array}{c}\text { Steel, } \\
\text { plasticine }\end{array}$ & $\begin{array}{c}\text { Open die } \\
95 \times 75 \times \text { L } 200 \\
\end{array}$ & 1000 & $10-25 \%$ & - & - & - \\
\hline [36] & Steel & $\begin{array}{cc}\text { Cogging } & \varnothing 90 \\
\text { x L 220 } & \\
\end{array}$ & $\begin{array}{c}800,1000 \\
1200\end{array}$ & 0.8 & - & Natural & 0.5 \\
\hline [8] & Aluminium & Compression & 450 & $80 \%$ & - & $\begin{array}{l}\text { Sphere, } \\
\text { cylinder }\end{array}$ & $\begin{array}{c}0.01,0.05, \\
0.1,0.2\end{array}$ \\
\hline [8] & $\begin{array}{c}\text { Steel, } \\
\text { Pb-valid. }\end{array}$ & $\begin{array}{l}\text { Open die } \\
\varnothing 40 \text { and } 35 \times 35 \times 1 \\
\text { L36 }\end{array}$ & $900-1200$ & $30 \%$ & $0.02-2$ & Open cylinder & 0.05 \\
\hline [37] & Steel & $\begin{array}{l}\text { Open die } \\
\varnothing 25 \times 40\end{array}$ & $1150-1200$ & $42 \%$ & - & $\begin{array}{l}\text { Sphere, } \\
\text { cylinder, } \\
\text { tetrahedron }\end{array}$ & $0.025-0.125$ \\
\hline [38] & Aluminum & $\begin{array}{l}\text { Multi-pass } \\
\text { forging }\end{array}$ & 420 & $1.3-8.9$ & $0.02-0.2$ & Natural & 0.001 \\
\hline
\end{tabular}

Table 1: Tested conditions regarding the studies on forging processes ("-" = unavailable data).

\begin{tabular}{|c|c|c|c|c|c|c|c|}
\hline Source & Material & $\begin{array}{l}\text { Process, billet } \\
\text { dim. (mm) }\end{array}$ & $\mathrm{T}\left({ }^{\circ} \mathrm{C}\right)$ & $\begin{array}{c}\text { Reduc. per } \\
\text { pass }\end{array}$ & $\begin{array}{l}\text { Roll diam } \\
(\mathrm{mm})\end{array}$ & Void shapes & $\begin{array}{c}\text { Void/sheet } \\
\text { ratios }\end{array}$ \\
\hline [3] & $\begin{array}{c}\text { Steel, } \\
\text { plasticine }\end{array}$ & Multipass & 1100 & $2-20 \%$ & - & Artificial & 0.05 \\
\hline [32] & Steel & $\begin{array}{l}\text { Multipass, } \\
200 \times 200\end{array}$ & 1200 & $4-16 \%$ & 450 & 2D Cyl. & 0.25 \\
\hline [39] & Steel & $\begin{array}{c}\text { 3-pass, } \\
\mathrm{H} 20 \times 150 \times 80\end{array}$ & $900-1200$ & $30,50,70 \%$ & 300 & Half-open & 0.06 \\
\hline [35] & $\begin{array}{c}\text { Steel, } \\
\text { plasticine }\end{array}$ & $\begin{array}{c}1-\text { pass, } \\
80 \times 60 \times 200\end{array}$ & 1000 & $8-33 \%$ & 220 & $\begin{array}{c}\text { Open } \\
\text { cylinder }\end{array}$ & - \\
\hline$[26]$ & Steel & $\begin{array}{c}\text { Multipass, } \\
137 \times 137 \text { or } \\
365 \times 265\end{array}$ & $1100-1200$ & $2-15 \%$ & $510-670$ & $\begin{array}{c}\text { Natural }+ \\
\text { Artificial } \\
\end{array}$ & $0.015-0.06$ \\
\hline \multirow[t]{2}{*}{ [40] } & \multirow[t]{2}{*}{ Aluminium } & $\begin{array}{c}2-\text { pass } 3 \times 0.6 \times 0.6 \\
\text { (samples) }\end{array}$ & pass $400^{\circ} \mathrm{C}(50 \%)$, & pass $320^{\circ} \mathrm{C}(50 \%)$ & - & \multirow[t]{2}{*}{$\begin{array}{c}\text { Natural } \\
\text { (X-ray } \\
\text { tomo) }\end{array}$} & \multirow[t]{2}{*}{$\begin{array}{l}1.7-8.3 \\
\times 10^{-3}\end{array}$} \\
\hline & & Compression & 540 & $6-60 \%$ & - & & \\
\hline
\end{tabular}

Table 2: Tested conditions regarding the studies on rolling processes ("_" = unavailable data). 
As for forging, the temperature gradient between the skin and the core of the workpieces was shown to improve void closure.

Rolling of aluminium was studied by Toda et al. [40]. The study dealt with a succession of rolling passes at various temperatures. A diffuse state of voids was tracked using X-ray microtomography according to various compression ratios and annealing periods. A geometry dependence was observed regarding void closure. An increase of void fraction was also pointed out during high temperature exposure, such as void growth or reopening of closed voids.

\subsubsection{Considered void states}

Artificial model holes were generally used to investigate the influence of parameters on void closure. The geometries were typically spheroidal or cylindrical.

Hot compression tests on aluminum samples containing cylindrical voids were conducted by Kakimoto et al. [8]. The study showed that the critical reduction required for complete void closure is mainly influenced by the height of the void (in the compression direction). The perpendicular dimension did not show any significant effect on void closure.

Closure mechanisms were discussed by Chen et al. [37] with respect to various void shapes (spherical, tetrahedral, and cylindrical), at different positions in a billet under compression. Long cylindrical voids presented a two-stage mechanism: firstly, the upper and lower surfaces rapidly entered into contact, and secondly, the small subsequent holes were more hardly closed up. It was also shown that tetrahedral voids were longer to completely close than spherical voids.

According to Chen et al. [37], the position in the billet has an impact on the closure rate. Closure was faster in the center of the billet. In the technical report Improsound [26], rolling trials were performed in order to compare different initial states. A billet was designed to contain several pre-defined void states that were inserted in its center. The pre-defined states were a $3 \times 3$ matrix of holes, a central single hole, and a natural porosity state. From metallographic examinations, it was observed that the hole in the center of the billet was completely closed, whereas those off-center were only partially closed.

The effect of the hole's position in the billet was also discussed by Wang et al. [39]. In these experiments, the holes were drilled in the direction perpendicular to the rolling direction and were drilled from the surface of the billet, providing half-opened holes. This contrasts with the holes defined in [26], which were oriented along the deformation direction and fully embedded in the billet. In the rolling trials performed by Wang et al. [39], the holes were better closed when positioned near the billet's surface. This result contrasts with the results obtained in [26] and points out the dependence of void closure to initial void shape and process conditions. It was also shown that shear is helpful for void closure.

From the rolling trials in the Improsound report [26], it was also observed that natural holes are harder to close than artificial drilled holes. This result is in good agreement with the results from Chen et al. [37], mentioning that in the case of complex initial void shapes, subsequent small voids are created during compression and are more hardly eliminated. Simple void geometries might therefore not fairly represent the closure behavior of natural voids.

The non-negligible influence of initial state was also demonstrated in Toda et al. [40]. Different closure behaviors were observed using 3D X-ray microtomography on Al-Mg alloy containing hydrogen micropores with various initial geometries. Some micropores remained visible after $60 \%$ compression, while others were completely closed. A combination of effects related to initial shape and position was the most plausible explanation.

\subsection{Criteria for void closure}

Keife and Ståhlberg [21] studied the deformation of round and square voids in a rigid-perfectly plastic material. They proposed a simple upper bound model based on the plane-strain condition, considering two different simple deformation modes around the voids. They concluded that the reduction $R_{c}$ necessary for complete void closure is a function of initial void volume fraction $V_{0}$, such that $R_{c} \sim V_{0}^{1 / 2}$. 
Tanaka et al. [5] proposed the use of the hydrostatic integration $Q$ as an indicator for void closure. The parameter $Q$ is the integral of stress triaxiality ratio $T_{X}=\frac{\sigma_{m}}{\bar{\sigma}}$ over the cumulated strain:

$$
Q=\int_{0}^{\bar{\varepsilon}}-T_{X} d \bar{\varepsilon}
$$

Nakasaki et al. [35] discussed the use of $Q$ as a parameter for void closure in hot forging and rolling conditions. Based on experimental and numerical results, an expression for the total void area reduction was obtained by linear regression. In the case of rolling, the hydrostatic integration parameter was revised to $Q^{+}=Q+0.024$, according to the observations that were made.

Hydrostatic integration was later used by Kakimoto et al. [8] to compare the closure of a void in different configurations of forging. In this study, numerical simulations were performed after validations using experiments on lead billets. A cylindrical hole was drilled through the billet with a void-to-billet diameter ratio of 0.05 , and multi-pass forging was performed. It was found out that the critical value of hydrostatic integration for complete void closure is $Q \geq 0.21$. The authors used this criterion to investigate four forging parameters and proposed industrial improvements regarding process design. Although the qualitative results regarding process optimization show great interest, a generalization of the value of the $Q$-criterion remains questionable for further processes. In this paper, experimental validations were performed using workpieces containing a drilled open-hole, which may have a rather different behaviour than an internal void.

Recently Chen and Lin [41] used the $Q$ criterion to study the evolution of shape parameters in the three directions $x, y, z$. They introduced a tridimensional version of the $Q$ criterion, using three values $Q_{i} \quad(i \in\{x, y, z\})$. The authors proposed a phenomenological expression to fit the aspect ratios of an ellipsoidal void according to $Q_{i}$.

$$
S_{i}=\left(C_{1}+S_{i 0}\right) \exp \left(-Q_{i} / C_{2}\right)+C_{3}, \quad \text { with } \quad Q_{i}=\int_{0}^{\bar{\varepsilon}} \frac{s_{i}}{\bar{\sigma}} d \bar{\varepsilon},
$$

where $s_{i}$ is the the component of the stress deviator tensor $\mathbf{s}$ in the $i$ direction. $S_{i}$ and $S_{i 0}$ are the aspect ratios and their initial values, respectively. $C_{1}, C_{2}$ and $C_{3}$ are fitting coefficients that were obtained using FE-simulations. Fitting values were obtained for several positions in a billet under a given forging process.

Tanaka et al. [5] also proposed an empirical void closure parameter $V C P$ based on $Q$ value, with a series of six coefficients $C_{i j}$ obtained by linear regression based on numerical simulations of compression:

$$
V C P=\sum_{i=0}^{2} \sum_{j=0}^{2-i} C_{i j}[\ln (1+\bar{\varepsilon})]^{i}[\ln (1-Q)]^{j},
$$

The parameter returns a degree of closure $(0-100 \%)$ of a virtually existing void, at any position in the billet. In the technical report Improsound [26], a wide campaign of numerical simulations and experimental observations about hot rolling was performed, and $C_{i j}$ coefficients were identified. Process design was performed using maps of void closure parameter obtained using the previous model.

A linear stress-triaxiality-based (STB) model for void closure was introduced in the commercial code FORGE [42] [43] and was implemented as:

$$
\frac{\Delta V}{V_{0}}=K_{c} T_{X} \Delta \bar{\varepsilon} .
$$

The variation of void volume fraction at each increment step is assumed proportional to the product of stress triaxiality ratio with incremental strain. In this equation, the proportionality coefficient $K_{c}$ was identified 
using linear regression from $\mathrm{FE}$ simulation. The value $K_{c}=5$ is proposed in [43], which provides a first approximation of the volume evolution of a single spherical void during compression of a cylindrical billet. Note that for the particular case of constant stress triaxiality ratio, Eq. (4) becomes:

$$
\frac{V}{V_{0}}=1+K_{c} T_{X} \bar{\varepsilon} .
$$

In the general case with non-constant stress triaxiality ratio, the actual void volume can be obtained by summing $\Delta V$ in Eq. (4) over the increments of deformation. In fact, the sum $\sum_{0}^{t} T_{X} \Delta \bar{\varepsilon}$ can be seen as the discretized form of $Q$ in Eq. (1),

$$
\sum_{0}^{\bar{\varepsilon}} \frac{\Delta V}{V_{0}}=K_{c} \sum_{0}^{\bar{\varepsilon}} T_{X} \Delta \bar{\varepsilon} \quad \approx K_{c} \int_{0}^{\bar{\varepsilon}} T_{X} d \bar{\varepsilon}=K_{c}(-Q) .
$$

Using the value $Q=0.21$ proposed by Kakimoto et al. [8] for complete closure, the predicted volume reduction can be computed as:

$$
\left.\frac{V}{V_{0}}\right|_{(Q=0.21)}=1+\sum_{0}^{\bar{\varepsilon}} \frac{\Delta V}{V_{0}}=1+5(-0.21) \approx 0 .
$$

As the final void volume equals to 0 , the void is completely closed up. Consequently, it can be said that Eq. (4) is in agreeement with the criterion proposed by Kakimoto et al. [8].

In all the studies presented above, the void-to-billet dimension ratio remained relatively large, i.e. around an average value of 0.1. Though, a large number of tiny voids usually exist in workpieces [26]. Tiny voids can hardly be considered by such a macroscopic approach, since their volume is very small and becomes negligible with respect to the volume of the workpiece. As pointed out in 2009 by Zhang and Cui [13] and Zhang et al. [44], there is at present a lack of applicable and accurate criterion in evaluating void closure. Based on micromechanical results from the literature, the authors proposed two numerical models for void closure. After a brief review of the main steps used within the micromechanical approach, the most recent criteria are presented and discussed in the following section.

\section{Micro-analytical approach}

In the micromechanical analysis, a single void in an infinite incompressible matrix is considered. The constitutive relations for the matrix are of the power-law type, with $m$ the power exponent:

$$
\mathbf{s}=\frac{2}{3} \frac{\sigma_{0}}{\dot{\varepsilon_{0}}}\left(\frac{\dot{\bar{\varepsilon}}}{\dot{\varepsilon_{0}}}\right)^{m-1} \dot{\boldsymbol{\epsilon}}, \quad \text { with } \operatorname{tr}(\dot{\boldsymbol{\epsilon}})=0,
$$

where $\dot{\boldsymbol{\epsilon}}$ is the strain-rate tensor, $\mathbf{s}$ is the deviatoric part of the stress tensor $\boldsymbol{\sigma}, \dot{\bar{\varepsilon}}$ and $\dot{\varepsilon}_{0}$ are, respectively, the effective and the reference strain-rate, $\sigma_{0}$ is the reference stress. The evolution of the initial void is studied with respect to various mechanical parameters, for different types of materials which properties are controlled by the power exponent: linearly viscous materials $(m=1)$, rigid-perfectly plastic materials $(m=0)$, and the general case of non-linear viscous materials $(0<m<1)$.

A large number of studies regarding void evolution in an infinite matrix were reviewed by Huang and Wang [45]. In these studies, voids are typically assumed to have spheroidal or cylindrical shapes. Most studies do not consider any change of shape during deformation, and the resulting equations often become inappropriate for large deformations (which is generally the case to obtain void closure). 


\subsection{Rigid-perfectly plastic material}

\subsubsection{Gurson-based models}

Gurson [14] established a relation providing a yield criterion for porous materials, as a function of void volume fraction $f$. The void evolution $\dot{f}$ is governed by the condition of incompressibility of the matrix, leading to a simple void growth law given by:

$$
\dot{f}=(1-f) \operatorname{tr}\left(\dot{\boldsymbol{\epsilon}}^{p l}\right),
$$

where $\dot{\boldsymbol{\epsilon}}^{p l}$ is the plastic strain-rate tensor. To obtain a yield criterion for porous materials, the material model used in Gurson's analysis is rigid-perfectly plastic $(m=0)$. A spherical cell, composed of matrix material containing a concentric spherical void, was considered. Based on cell calculations, an upper bound solution for yield criterion was proposed for the macroscopic behavior of porous metals.

Tvergaard [46] proposed corrective coefficients to Gurson's model. Gurson-Tvergaard's model is widely used in the framework of ductile fracture due to void nucleation, growth and coalescence. Additionally, Tvergaard and Needleman [47] introduced a modified void volume fraction $f^{*}=f^{*}(f)$ for $f>f_{c}$, where $f_{c}$ is a critical value over which the coalescence phenomenon takes place. Void coalescence phenomenon will not occur in the case of void closure.

Various modified Gurson-based models are available in the literature, taking into account some additional mechanisms, such as isotropic and kinematic hardening, and the effect of strain-rate sensitivity. Recently, Scheyvaerts et al. [48] extended Gurson's model to spheroidal voids in shear and tension conditions, using a constitutive law considering both elastic regime and plastic hardening. More recently, Madou and Leblond $[49,50]$ extended the Gurson model and proposed a yield criterion for porous material containing arbitrary ellipsoidal voids.

However, very few studies focused on the evolution of void volume during closure. From the GursonTvergaard model, Ragab [51] established an expression to evaluate the volumetric strain-rate of a spherical void,

$$
\frac{\dot{V}}{3 \dot{E}_{e} V}=\frac{q_{1} q_{2}}{2} \sinh \left(\frac{3}{2} q_{2}\left|T_{X}\right|\right),
$$

where $\dot{E}_{e}$ is the remote equivalent strain, and $q_{1}=1.5, q_{2}=1.0$ are the coefficients obtained by Tvergaard [46]. In this equation, the void is assumed to remain spherical.

\subsubsection{Analytical solutions}

Rice and Tracey [10] proposed a model for the evolution of a spherical void in a rigid-perfectly plastic matrix $(m=0)$. In the analysis, the void undergoes an uniaxial loading under axisymmetric stress conditions. As no analytical expression can be obtained, approximate Rayleigh-Ritz solutions were obtained using the variational principle. The velocity field is defined as:

$$
\mathbf{v}=\mathbf{v}_{0}+\tilde{\mathbf{v}},
$$

with $\mathbf{v}_{0}=\dot{\mathbf{E}} \cdot \mathbf{x}$ the remote velocity field, where $\dot{\mathbf{E}}$ is the remote strain-rate tensor at infinity, $\mathbf{x}$ is the spatial coordinates vector, and $\tilde{\mathbf{v}}=D \mathbf{v}_{D}+\mathbf{v}_{E}$ is the local velocity change due to the presence of a void. The first term $\mathbf{v}_{D}$ thus describes the spherically symmetric deformation due to the volume change of the void, where $D$ is the normalized dilatation rate, and $\mathbf{v}_{E}$ describes the shape change of the void. Under high stress triaxiality, it is shown that the influence of $\mathbf{v}_{D}$ is much larger that the one of $\mathbf{v}_{E}$, and the void's shape change can be neglected. The approximation of high stress triaxiality thus leads to:

$$
\mathbf{v}=\dot{\mathbf{E}} \cdot \mathbf{x}+D \mathbf{v}_{D} .
$$

The minimum principle, which consists in minimizing a functional $F(\mathbf{v})$ is used to obtain a velocity field. The normalized dilatation rate $D$ is obtained as:

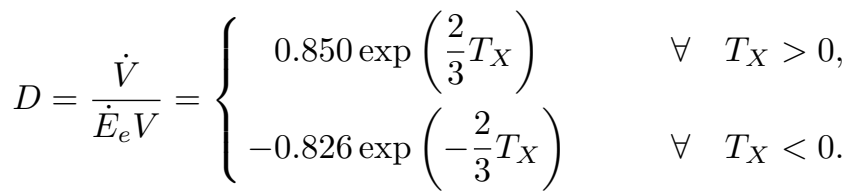


where $\dot{E}_{e}=\sqrt{\frac{2}{3} \dot{\mathbf{E}}: \dot{\mathbf{E}}}$ is the remote equivalent strain. The coefficients are analytical values that result from the Rayleigh-Ritz procedure.

\subsection{Linear viscous material}

In the case of linear viscous (or Newtonian) materials $m=1$, analytical solutions were calculated by Budiansky et al. [11] for an extended number of constant stress triaxiality ratios $T_{X}=\frac{\sigma_{m}}{\bar{\sigma}}$. The volume rate of a sphere may be expressed as:

$$
\frac{\dot{V}}{\dot{\bar{\varepsilon}} V}=\frac{9}{4} T_{X}
$$

\subsection{Nonlinear viscous material}

\subsubsection{Analytical solutions}

Budiansky et al. [11] studied the deformation of a spherical void in a nonlinear viscous matrix. As for the case presented above, the authors showed that no analytical solution may be obtained, and the RayleighRitz procedure was used. The high stress triaxiality (HST) approximation is also used to only consider the radially symmetric contribution of the velocity field. Using this approximation, the volumetric strain-rate of the spherical void can be written as:

$$
D_{s p}^{H S T}=\frac{\dot{V}}{\dot{E}_{e} V}=\frac{3}{2}\left(\frac{3 m}{2}\left|T_{X}\right|+G(m)\right)^{\frac{1}{m}} \quad \forall \quad\left|T_{X}\right| \gg 1 .
$$

In the case of low stress triaxiality $(L S T)$, an expression for volumetric strain-rate is proposed by [52]:

$$
D_{s p}^{L S T}=\frac{\dot{V}}{\dot{E}_{e} V}=\frac{3}{2}\left(\frac{3 m}{2}+G(m)\right)^{\frac{1}{m}}\left|T_{X}\right| \quad \forall \quad\left|T_{X}\right| \ll 1 .
$$

In these equations,

$$
\left\{\begin{array}{lll}
G(m)=(1-m)(1+(\ln (3)-2 / 3) m) & \approx(1-m)(1+0.432 m) & \forall \quad T_{X}>0 \\
G(m)=(1-m)\left(1+\frac{2 \pi}{9 \sqrt{3}} m\right) & \approx(1-m)(1+0.403 m) & \forall \quad T_{X}<0 .
\end{array}\right.
$$

Note that for $m=1, G(m)=0$ and both Eqs. ((15), (16)) reduce to Eq. (14).

Duva and Hutchinson [12] proposed an extension of Eqs. (15) and (16) for any stress triaxiality ratios, using an interpolation approximation. The expression of volumetric strain-rate for a sphere $D_{s p}$ gives:

$$
D_{s p}=\left(\frac{\dot{V}}{\dot{E}_{e} V}\right)_{s p}=\frac{3}{2}\left(\frac{3 m}{2}\left|T_{X}\right|+G(m)\right)^{\frac{1}{m}}+c_{1}\left|T_{X}\right|+c_{2} \quad \forall \quad T_{X},
$$

which, in the case of void closure $\left(T_{X}<0\right)$, leads to:

$$
D_{s p}=\left(\frac{\dot{V}}{\dot{E}_{e} V}\right)_{s p}=\frac{3}{2}\left(-\frac{3 m}{2} T_{X}+(1-m)(1+0.403 m)\right)^{\frac{1}{m}}-c_{1} T_{X}+c_{2}
$$

where parameters $c_{1}$ and $c_{2}$ are tabulated functions of $m$ [13]. The volumetric strain-rate is plotted in Fig. 1a for $m=0.2$. Note that there is a slight difference between values proposed by the generalized formula and the solution given by Budiansky et al. [11] using the high stress triaxiality approximation. The authors argued that the solution in Eq. (15) underestimates the deformation rate, due to the approximation made by Budiansky et al. [11] on the velocity field. Indeed, the relative error obtained between the generalized formula Eq. (19) and both Eqs. (15) and (16) on their respective domain of validity is plotted in Fig. $1 \mathrm{~b}$. A greater difference (about 20-25\%) can be seen around $\left|T_{X}\right|=1$, i.e. at the boundary between both 


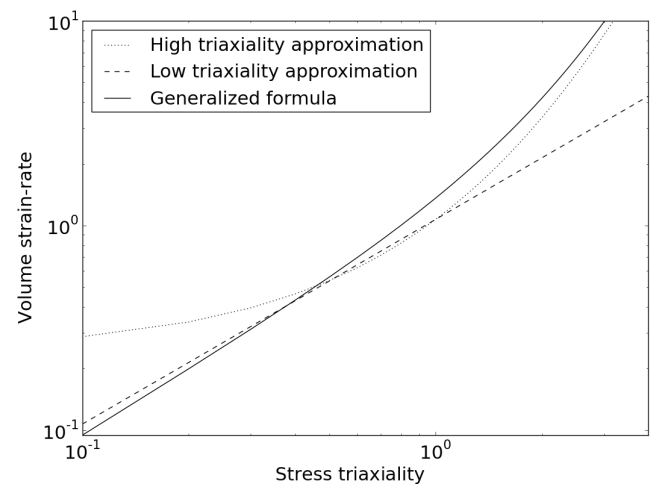

(a) $m=0.2$

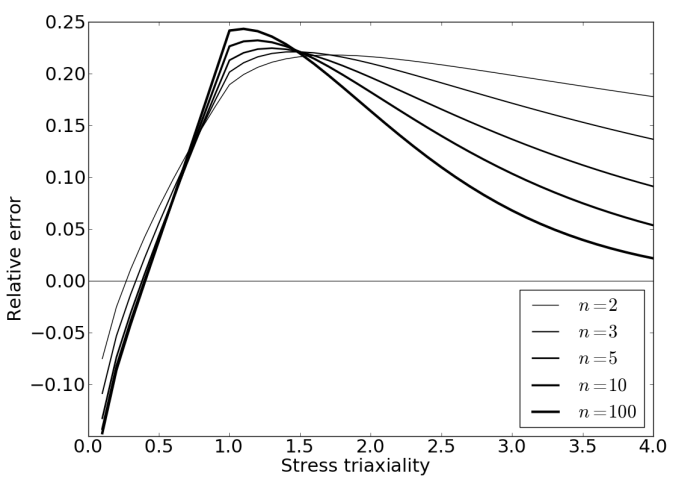

(b)

Figure 1: (a) Normalized volumetric strain-rate for a sphere $D_{s p}$ given by Eq. (19) (Generalized formula), compared to high and low stress triaxiality approximations given by Eq. (15) and Eq. (16), respectively; and (b) the relative deviation between Eq. (19) and Eq. (15) or Eq. (16) on their domain of validity, for various values of $m$ (given as $n=1 / m$ ).

approximations. The generalized formula for $D_{s p}$ was proposed in order to approach Eqs. (15) and (16) on their respective domain of validity, and thus considers the same approximations. Note that the relative error is slightly negative at very low stress triaxiality values, without great influence of $m$-value.

A similar analysis was performed by He and Hutchinson [53], considering the deformation of a pennyshaped crack. The Rayleigh-Ritz solution for the volumetric strain-rate of a crack gives:

$$
\left(\frac{\dot{V}}{\dot{E}_{e} V}\right)_{c r}=\frac{D_{c r}}{\lambda}=\frac{1}{\lambda} \frac{6}{\pi \sqrt{1+3 m}}\left(\left|T_{X}\right|+\frac{2}{3}\right) \text { for } \lambda \ll 1,
$$

where $\lambda=a / b$ is a shape factor, as illustrated in Fig. 2 ( $\lambda \ll 1$ for a penny-shaped crack).

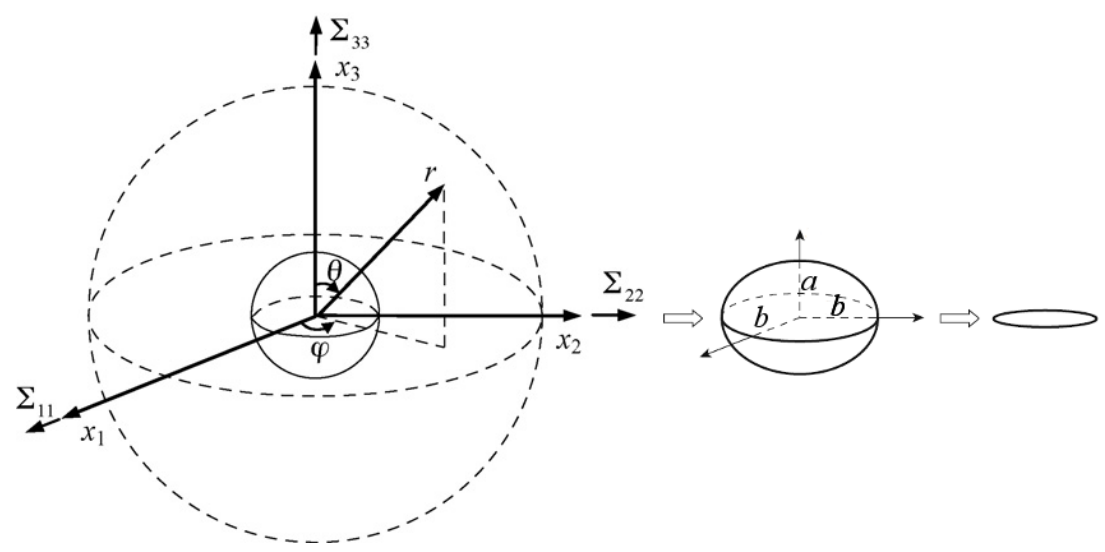

Figure 2: Void evolution from spherical shape to a crack. Reproduced with permission from [13, 44].

Using an interpolation scheme, Zhang and Cui [13] proposed an expression for the transition state from spherical to finally crack-like mode. The evolution of void volume can be expressed as:

$$
\frac{V}{V_{0}}=\left|\frac{D_{\dot{\lambda}} \exp \left(-D_{c r} E_{e}\right)-D_{c r} \exp \left(-D_{\dot{\lambda}} E_{e}\right)}{D_{\dot{\lambda}}-D_{c r}}\right| \exp \left(D_{s p} E_{e}\right),
$$

where $D_{\dot{\lambda}}$ corresponds to the change-rate of the aspect ratio of a spherical shape, which is obtained using a Rayleigh-Ritz procedure on spherical voids: 


$$
D_{\dot{\lambda}}=\left(\frac{\dot{\lambda}}{\dot{E}_{e}}\right)=2.5-(1-m)\left[(29-45 m)\left(1+\frac{3}{3 T_{X}-2}\right)^{3}-\frac{2}{9}\right] \text {. }
$$

\subsubsection{Semi-analytical solution}

From the analytical model in Eq. (19) for a spherical void (assumed to remain spherical) the same authors alternatively proposed a semi-analytical extension for considering the change of shape during deformation [44]. The authors introduced an empirical dependence to void shape $\lambda$, assuming that it depends on the cumulated strain, only. The coefficient $c_{2}$ in Eq (19) is replaced by a polynomial function of cumulated strain and leads to Eq. (23). The values for parameters $c_{i}, i \in\{1,2,3,4\}$ are numerically obtained using FE calculations based on a cubic cell model containing a spherical void (Fig. 3). The volume of void is obtained using different values of stress triaxiality ratio $T_{X}$, and are given in [44] for various values of $m$.
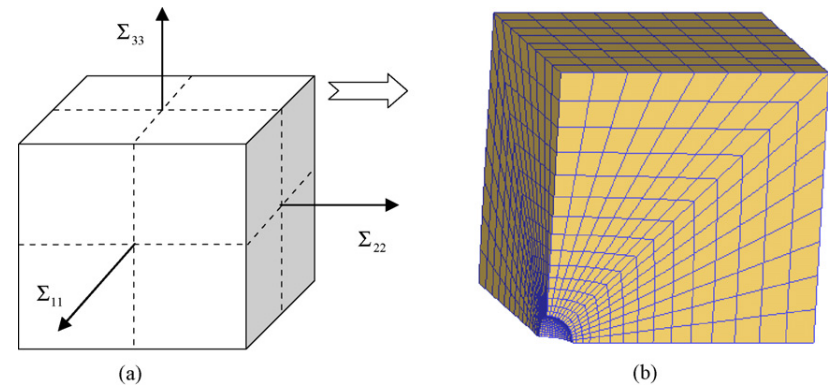

(b)

Figure 3: The cubic cell model used for obtaining $c_{i}$ values. Reproduced with permission from [44].

Note that the dependence in triaxiality ratio is consistent with the results presented in Section 2 dealing with the product of stress triaxiality ratio with effective strain. Eq. (23) is also in good agreement with qualitative results from process studies presented above in Section 2, which relates that pore closure is faster for high reduction ratios and large negative stress triaxiality ratios. Here, the effect of power exponent, i.e. of a material property, is also considered.

$$
\frac{\dot{V}}{\dot{E}_{e} V}=\frac{3}{2}\left(\frac{3 m}{2}\left|T_{X}\right|+G(m)\right)^{\frac{1}{m}}+c_{1}\left|T_{X}\right|+3 c_{2} E_{e}^{2}+5 c_{3} E_{e}^{4}+c_{4} .
$$

Integration of Eq. (23) over the strain path (assuming constant triaxiality ratio during deformation) leads to:

$$
\frac{V}{V_{0}}=\exp \left(-E_{e}\left[\frac{3}{2}\left(\frac{3 m}{2}\left|T_{X}\right|+G(m)\right)^{\frac{1}{m}}+c_{1}\left|T_{X}\right|+c_{2} E_{e}^{2}+c_{3} E_{e}^{4}+c_{4}\right]\right) .
$$

The authors studied the evolution of void volume as a function of macroscopic strain $E_{e}$ for several values of power exponents and stress triaxiality ratios. It is shown that stress triaxiality might considerably increase void closure, as illustrated in Fig. 4a, and that decreasing $m$ has a positive influence on void closure, as shown in Fig. 4b. It is noteworthy that large stress triaxiality have an effect since the earliest stages of void closure, by increasing the initial rate of closure. The macroscopic strain required for void closure is thus reduced by increasing stress triaxiality.

Lee and Mear [54, 55] discussed the validity of Gurson's models regarding a material containing aligned spheroidal voids in axisymmetric loading conditions. Various shapes were considered, such as penny-shaped, oblate, prolate, or cylindrical voids. The authors provided qualitative results regarding the evolutions of spheroidal voids under various triaxiality ratios. It is pointed out that initial void shape may have a significant influence on void closure. Randomly orientated spheroidal are also discussed. It is concluded that it is extremely difficult to obtain accurate results, although bounds and estimates were proposed by [56]. 


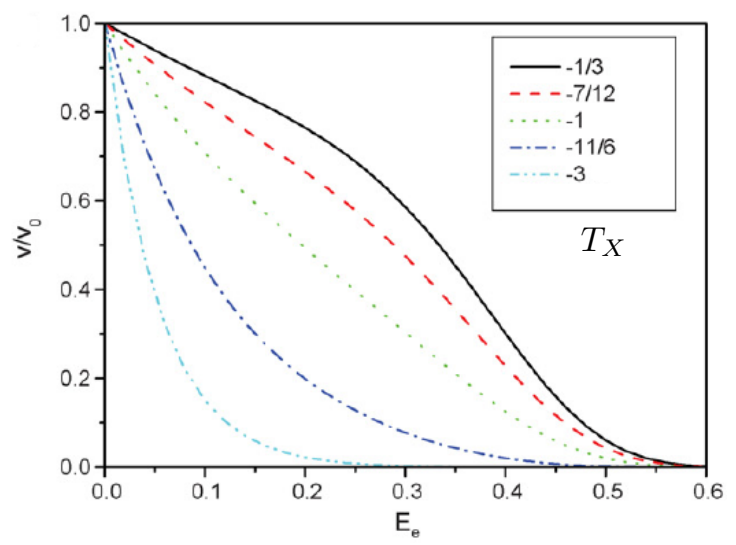

(a) Influence of $T_{X}$, for $m=1 / 3$

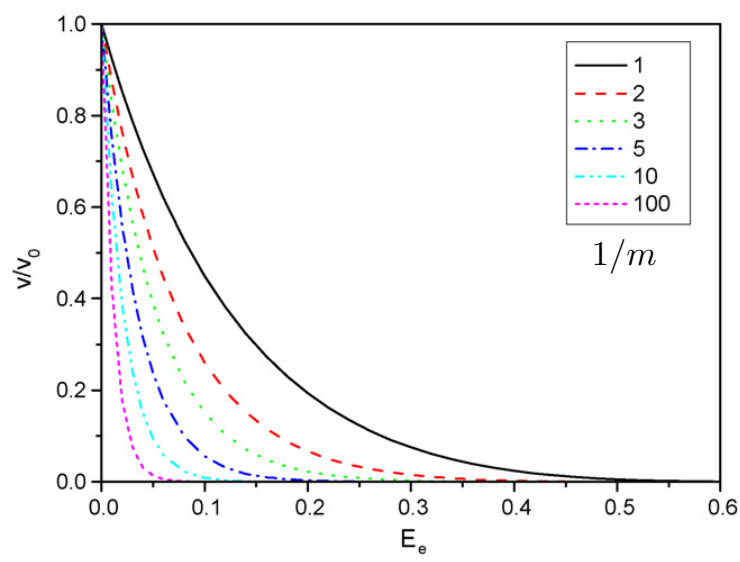

(b) Influence of power exponent $m$, for $T_{X}=-3$

Figure 4: Effect of stress triaxiality ratio and of power exponent on void closure. Reproduced with permission from [44].

The qualitative data in [55] were used by Zhang and coworkers $[13,44]$ to compare with the results obtained from Eqs. (21) and (24).

\section{Comparison of models}

\subsection{Comparison by Zhang and Cui [13]}

The analytical model in Eq. (21) was discussed by Zhang and Cui [13]. The results were compared with data from [55] in Fig. 5. As it can be seen for $m=0.33$, the interpolation scheme and the numerical data are in very good agreement for all tested stress triaxiality ratios. The authors implemented Eq. (21) in a FE code to compute their prediction model at the macroscopic scale in a void-free process. They used the case of a billet under uniaxial compression, as shown in Fig. 6. The model was able to predict the volume of voids with very good accuracy, providing considerable reduction CPU time (the authors showed a reduction by a factor of 10).

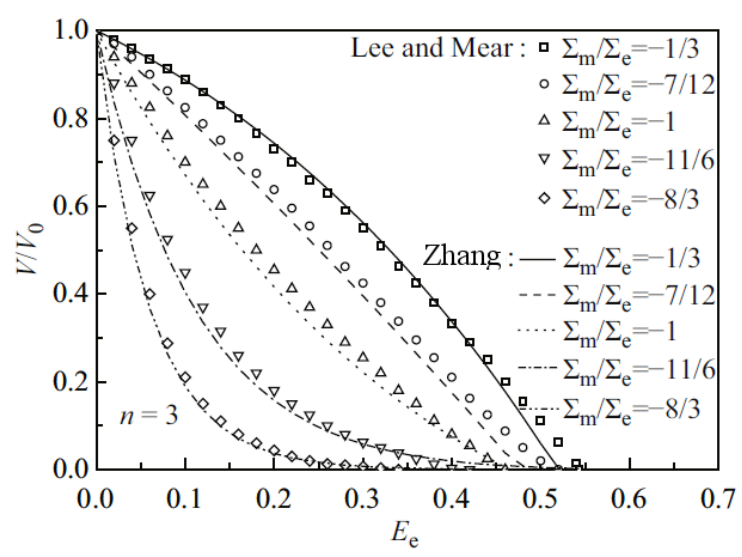

Figure 5: Comparison of void evolutions, with $m=0.33$, given by Eq. (21) and by Lee and Mear [55]. Reproduced with permission from [13]. 


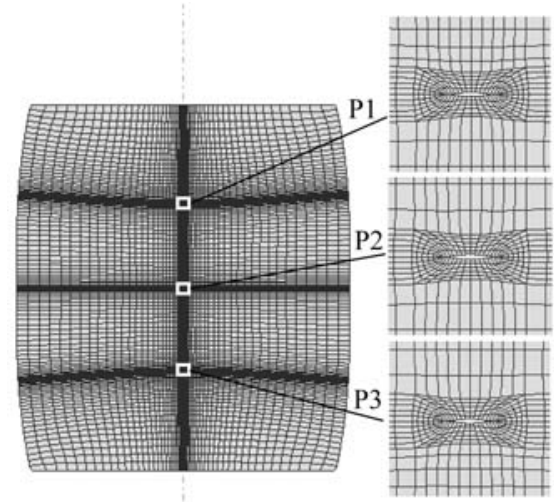

(a) Mounting void method (MVM)

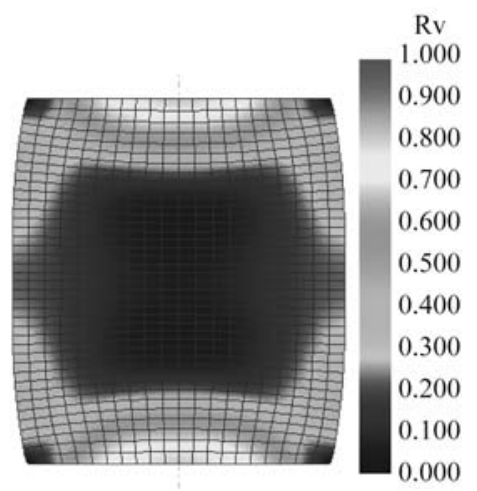

(b) Model method (MM)

Figure 6: Comparison of the results at $32 \%$ billet reduction. Reproduced with permission from [13].

\subsection{Comparison by Zhang et al. [44]}

Zhang et al. [44] compared their semi-analytical model (Eq. (24)) with the models of Gurson (G), GursonTvergaard (GT), Budiansky-Hutchinson-Slutsky (BHS), the results of Lee and Mear [54, 55], as well as the FE results that were used for calibration. The comparison is made for two values of stress triaxiality ratios and is presented in Fig. 7. The plot for G and GT-models were obtained using Eq. (10), with the values $\left(q_{1}, q_{2}\right)=(1,1)$ and $\left(q_{1}, q_{2}\right)=(1.5,1)$ respectively. The plot for BHS-model was obtained using Eq. (15). For very compressive stress triaxiality ratios $T_{X}=-2$, Fig. 7a illustrates that all models predict a roughly similar evolution of void volume, although G and G-T models seem to slightly overestimate void closure. For the less compressive triaxiality ratio $T_{X}=-0.6$, Fig. $7 \mathrm{~b}$ shows that two different behaviors are predicted by the models. This difference is attributed to the assumption made in the G, G-T, and BHS models, that the initial spherical (or spheroidal) void shape remains unchanged during deformation. This difference rises with strain $E_{e}$, since the actual shape of the void deforms towards a crack-shape. This difference is less marked with larger negative stress triaxiality ratios (Fig. 7a), as the change in aspect ratios is slighter. This observation was also made by [55]. This is coherent with the high triaxiality assumption of BHS model.

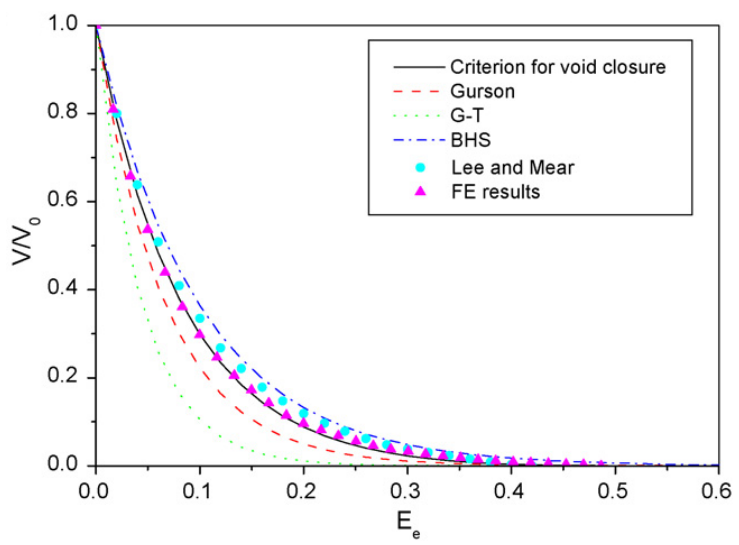

(a) $T_{X}=-2$

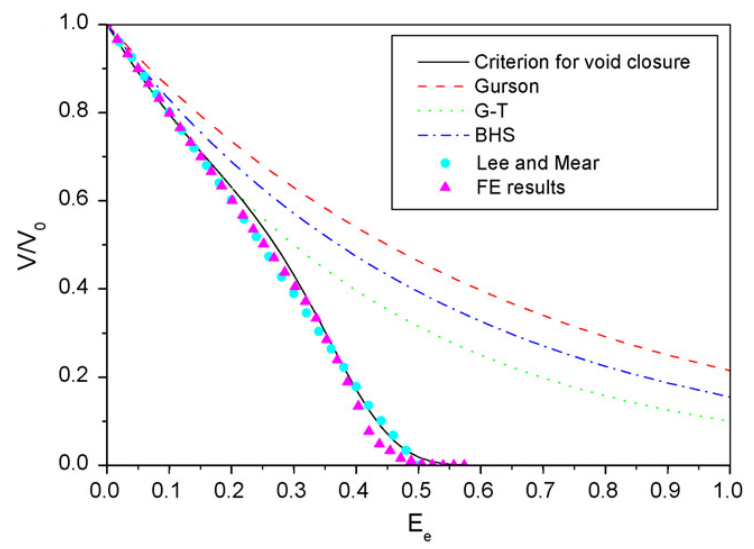

(b) $T_{X}=-0.6$

Figure 7: Comparison of the criterion of Zhang et al. [44] (Eq. (24)) plotted in black line, with data from literature and FE simulations on cell model, with $m=0.2$. Reproduced with permission from [44].

The model of Zhang et al. [44] was recently implemented in the commercial FE code DEFORM-3D ${ }^{\text {TM }}$ by Zhang et al. [57]. The influence of various process parameters on void closure was studied using upsetting, 
blocking and multi-pass forging. The influence of die-shapes is discussed in order to enhance void closure and thus material soundness. Although the model showed good agreement with the result from the literature regarding the evolution of a sphere under constant boundary conditions (Fig. 7), no validation of the model under complex loadings was presented. The accuracy of the presented results remains thus questionable in the case of industrial processes.

\subsection{Comparison of all models}

A comparison of all models is now proposed in order to discuss the reliability of the models within the range of values of interest for typical industrial applications. According to the literature, the stress triaxiality ratio $T_{X}$ and the material parameter $m$ are the two parameters that were taken into account. The range of stress triaxiality ratios is $T_{X}=[-1.2,0]$ in the present comparison. This range was defined according to numerical simulations of several industrial processes [58], such as hot forging and hot rolling. Several values of $m$ are considered in order to illustrate the dependence of the models to material behaviour.

In total, six values of stress triaxiality ratios $T_{X}$ and three values of $m$ were defined and void volume evolutions are plotted in Fig. 8. The six models are synthetically recalled in Table 3 with the values of coefficients that were used to plot the 18 configurations.

\begin{tabular}{cccc}
\hline Model & Type & Equation & Constants values \\
\hline STB [43] & Empirical & Eq. (4) & $K_{C}=5$ \\
Tanaka et al. [5] & Empirical & Eq. (3) & $C_{i j}($ Table 4$)$ \\
Gurson-Tvergaard [46] & Analytical & Eq. (10) & $q_{1}=1.5, q_{2}=1$ \\
Budiansky et al. [11] & Analytical & Eq. (15) & - \\
Duva and Hutchinson [12] & Analytical & Eq. (19) & $c_{1}$ and $c_{2}$ (Table 5) \\
Zhang and Cui [13] & Analytical & Eq. (21) & - \\
Zhang et al. [44] & Semi-analytical & Eq. (24) & $c_{1}, c_{2}, c_{3}, c_{4}$ (Table 6) \\
\hline
\end{tabular}

Table 3: Equations of the models used to plot Fig. 8.

\begin{tabular}{cccccc}
\hline$C_{00}$ & $C_{01}$ & $C_{02}$ & $C_{11}$ & $C_{12}$ & $C_{22}$ \\
\hline 0.0114 & 0.84 & -2.48 & 2.17 & 12.6 & -1.98 \\
\hline
\end{tabular}

Table 4: Values of coefficients $C_{i j}$ in Eq. (3), from Tanaka et al. [5].

\begin{tabular}{lcccccc}
\hline$m$ & 1.0 & 0.5 & 0.2 & 0.3 & 0.1 & 0.01 \\
\hline$c_{1}$ & 0. & 0.5951 & 0.7061 & 0.8049 & 0.9002 & 1.0066 \\
$c_{2}$ & 0. & -0.5479 & -0.6571 & -0.7340 & -0.7874 & -0.8329 \\
\hline
\end{tabular}

Table 5: Values of coefficients $c_{1}$ and $c_{2}$ in Eq. (19) resulting from analytic solutions from Duva and Hutchinson [12], tabulated in Zhang and Cui [13].

\begin{tabular}{lcccccc}
\hline$m$ & 1.0 & 0.5 & 0.2 & 0.3 & 0.1 & 0.01 \\
\hline$c_{1}$ & 0.5048 & 0.4911 & 0.6016 & 1.1481 & 2.9132 & 6.5456 \\
$c_{2}$ & 6.4675 & 0.8002 & -0.6981 & -4.2026 & -11.6464 & -15.3775 \\
$c_{3}$ & 14.2610 & 53.8018 & 72.6397 & 108.2114 & 185.5622 & 324.4417 \\
$c_{4}$ & -0.3379 & -0.2314 & -0.1243 & -0.2480 & -0.6511 & -1.9575 \\
\hline
\end{tabular}

Table 6: Values of coefficients $c_{1}, c_{2}, c_{3}$ and $c_{4}$ in Eq. (24) resulting from calibration using FE simulations obtained by Zhang et al. [44].

From Fig. 8, it can be seen that Gurson-Tvergaard curves coincides with the ones of Duva and Hutchinson [12] for $m=0.01$, even though their expressions are rather different. Gurson-Tvergaard was developed for 
perfectly-rigid plastic materials (which corresponds to the case $m=0$ ). The good agreement comes from the fact that both models are based on the same assumptions and consider the evolution of a spherical void. This is no longer the case for larger $m$ values, as the model of Gurson-Tvergaard is valid for perfectly-rigid plastic materials, exclusively.

Note that the simple behaviour law in Eq. (8) that is used in the analytical and semi-analytical models Budiansky et al. [11], Duva and Hutchinson [12], Zhang and Cui [13], Zhang et al. [44] may be insufficient to accurately model the behaviour of hot metals. Hot metal behaviour usually involve strain hardening and softening features that cannot be considered using Eq. (8).

The influence of material was not considered in any of both empirical models (STB Lasne [43], Tanaka et al. [5]).

The curves from Budiansky et al. [11] model tend to get closer to the ones of Duva and Hutchinson [12] for $\left|T_{X}\right| \leq 1$. This is coherent with the fact that Duva and Hutchinson [12] is an extension of Budiansky et al. [11] (based on high triaxiality assumption) to all values of $T_{X}$. Both models are superimposed in the case of linear viscous materials $(m=1)$, since both equations reduce to Eq. (14) for linearly viscous materials.

The comparisons made in Zhang and Cui [13] and Zhang et al. [44] covered the range $-2.7<T_{X}<-0.33$ (in Figs. 5 and 7). Both comparisons were made for a single value of $m$ (for $m=0.33$ and for $m=0.2$, respectively). In Fig. 8, both models are plotted over the range of interest for $T_{X}$, and for the three values of $m$. Rather good agreement between both models is observed over the range $-1.2<T_{X}<-0.4$ as well, notably for the value $m=0.3$. Void closure is obtained around similar strain values. Void evolution is roughly similar, although a few differences may be pointed out. The analytical model provides monotonous curves, whereas the semi-analytical model induces several changes of slope. The latter also exhibits an asymptotic final closure, unlike the analytical model that presents a rather steep decrease until complete closure.

Larger deviations can be observed for the less compressive triaxiality values $\left(-0.2<T_{X}<0.0\right)$, especially for extreme values of $m(m \rightarrow 0$ and $m=1)$. Such values of triaxiality were unfortunately not discussed in the papers, although they may require full attention, as they belong to the range of interest for industrial applications. Very different initial behaviours are predicted between the analytical model and the semianalytical model. Let us finally note that, for the analytical model, the value of strain that is required for complete closure using $T_{X}=0.0$ is lower than for $T_{X}=-0.2$, which is physically counter-intuitive. The best agreement between the analytical and semi-analytical models is obtained for $T_{X}=-0.4$, i.e. close to the particular case of uniaxial compression $\left(T_{X}=-\frac{1}{3}\right)$. The curves also show good agreement with the STB model, except for the value $m=1$ (although such a value remains excessively elevated regarding the ranges of interest within this work).

The empirical model of Tanaka et al. [5] systematically underestimates void closure, although the general tendency regarding the dependence on stress triaxiality is respected. However, the evolution of void volume with strain remains rather different from analytical models.

\section{Discussion}

The STB model and the model of [5] are based on empirical results that were obtained from experiments and numerical simulations. They were initially calibrated for the case of spherical voids using a given material law. Both models respect the general tendency relative to stress triaxiality ratio. They do not consider any dependence to material behaviour. Further calibration of these models is possible for considering additional parameters. However, new coefficients might at best predict void closure for a given geometry and a given material, and must be repeated for any configurations. Generalization is at present not permitted using such models.

Among all analytical models, the one from [13] clearly arises as the most advanced as it covers the largest range of stress triaxiality ratios, material behaviour, and considers the change in void shape during deformation. However, this model suffers from the fact that a sphere is exclusively considered. Indeed, it was 


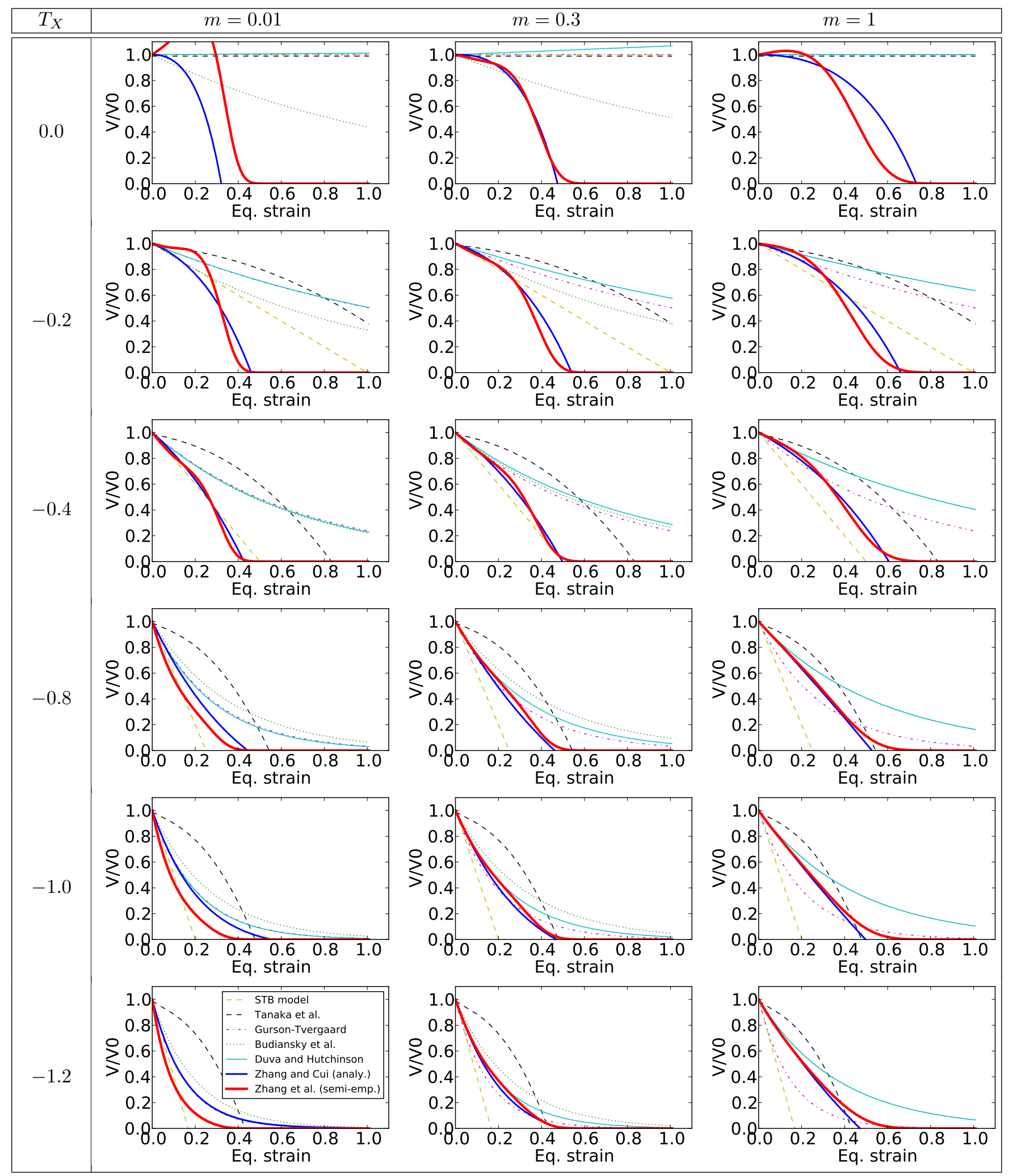

Figure 8: Comparison models given in Table 3 (STB model [43], Tanaka et al. [5], Gurson-Tvergaard [46], Budiansky et al. [11], Duva and Hutchinson [12], Zhang and Cui [13] and Zhang et al. [44]) over the range $-1.2<T_{X}<0.0$ and for $m=\{0.01,0.3,1\}$. 
shown [55] that initial void shape might significantly influence the void closure behaviour. The reliability of the model was not addressed in the literature regarding its use in a industrial context. In addition, some counter-intuitive observations were made at low compressive stress triaxiality ratios (Fig. 8).

The semi-analytical model from [44] provides a comparable prediction as the analytical model from the same authors. This model was used in [57] to design die shapes and pass schedules during hot forming processes using a finite element software. However, the model also suffers from the fact that spherical voids are exclusively considered. In addition, the validation cases that are presented by Zhang et al. [44] are compared to the results of Lee and Mear [55], in which the results were obtained under constant and uniform deformation cases. One can wonder the reliability of the model in the case of non-uniform loading paths, as mentioned in previous work [59] using a simple prediction model.

Initial void state (morphology and position) appears as a major potential improvement, as complex geometries were pointed out in the industrial review, and according to the significant influence that was qualitatively exhibited in literature. The dependence to mechanical state might also be further studied in order to better predict the phenomenon over the entire range of stress-triaxiality and deformation. The influence of material parameters might also be further studied, notably regarding actual behaviours of hot metals (e.g. strain hardening or softening effects).

Among all models that were considered in this paper, the stress state is described using the value of stress triaxiality ratio only, assuming axisymmetric boundary conditions. Nevertheless, it was shown [18] that the value of $T_{X}$ is not sufficient to completely define the stress state and the use of the Lode angle $\mu$ to complete the definition of the stress state is suggested. All models within this paper are thus implicitly based on the particular case $\mu= \pm 1$. Several authors studied the effect of the Lode angle on void growth [60,61] or phenomenological ductile damage models [62] and a non-negligible influence on void growth was shown, in particular for low stress triaxiality ratios. The use of this Lode angle parameter would thus be a major improvement for void closure models.

To study void closure with more accuracy, the meso-scale arises as a relevant approach. The use of a Representative Volume Element (RVE) was described in previous work [59]. In this paper, an accurate description of the initial void was obtained using real tridimensional morphologies that were obtained from $\mathrm{X}$-ray microtomography. Boundary conditions were also accurately applied in order to faithfully represent thermo-mechanical loadings from industrial processes. This approach enables an accurate description of void closure under real industrial conditions, involves relatively fast computations, and thus enables parametric sensitivity studies to be performed. Based on a wide campaign of RVE simulations, a new model for predicting void closure was established and will be presented in a forthcoming publication.

\section{Conclusions}

- In the literature, void closure is studied according to two different main approaches: a macroscopic approach and a micro-analytical approach. The former is hardly generalizable as it is case-dependent. The latter involves a certain number of assumptions that are generally far from industrial issues, particularly in terms of void shape.

- Considering the voids morphology and position arises as a great potential improvement for current semi-analytical existing models.

- Dependance to mechanical state is also of prime importance. Stress triaxiality is systematically used in the literature for the prediction of void closure. However, the use of Lode angle is not currently used to predict void volume evolution during closure, although it is already commonly used in models for ductile fracture and porous materials. The Lode angle thus arises as a great potential improvement as well.

- Finally, due to the limitations of both macroscopic and micro-analytical approaches to study void closure, an alternative meso-scale approach is suggested. Based on a wide campaign of $\mathrm{FE}$ simulations 
at the RVE-scale, new prediction models can be elaborated. Very promising results were obtained using this approach [59] regarding the geometry-dependence of void closure under various stress states.

\section{Acknowledgments}

The authors would like to thank Prof. Zhenshan Cui and Prof. Xiaoxun Zhang for providing detailed precisions regarding their work and permission to use several figures. The authors would like to gratefully thank TIMET Savoie, as well as Aubert\&Duval, Ascometal CREAS, Creusot Forge (Areva), Industeel (Arcelormittal) and Constellium for funding this research.

[1] Park, C.Y., Yang, D.Y.. A study of void crushing in large forgings I: Bonding mechanism and estimation model for bonding efficiency. Journal of Materials Processing Technology 1996;57(1-2):129-140.

[2] Ståhlberg, U., Keife, H., Lundberg, M., Melander, A.. A study of void closure during plastic deformation. Journal of Mechanical Working Technology 1980;4(1):51-63.

[3] Wallerö, A.. Closing of a central longitudinal pore in hot rolling. Journal of Mechanical Working Technology $1985 ; 12(2): 233-242$.

[4] Hwang, Y.M., Chen, D.C.. Finite element simulations on void closure behaviour inside the sheet during sheet rolling processes. Proceedings of the Institution of Mechanical Engineers, Part B: Journal of Engineering Manufacture $2002 ; 216(9): 1227-1237$.

[5] Tanaka, M., Ono, S., Tsuneno, M.. Factors contributing to crushing of voids during forging. Journal of JSTP 1986;27 (306):927-934. (translated from Japanese).

[6] Dudra, S.P., Im, Y.T.. Analysis of void closure in open-die forging. International Journal of Machine Tools and Manufacture 1990;30(1):65-75.

[7] Banaszek, G., Stefanik, A.. Theoretical and laboratory modelling of the closure of metallurgical defects during forming of a forging. Journal of Materials Processing Technology 2006;177(1-3):238-242.

[8] Kakimoto, H., Arikawa, T., Takahashi, Y., Tanaka, T., Imaida, Y.. Development of forging process design to close internal voids. Journal of Materials Processing Technology 2010;210(3):415-422.

[9] Chen, J., Chandrashekhara, K., Mahimkar, C., Lekakh, S.N., Richards, V.L.. Study of void closure in hot radial forging process using 3D nonlinear finite element analysis. The International Journal of Advanced Manufacturing Technology 2012;62(9-12):1001-1011. doi: bibinfo\{doi\} \{10.1007/s00170-011-3876-3\} .

[10] Rice, J.R., Tracey, D.M.. On the ductile enlargement of voids in triaxial stress fields. Journal of the Mechanics and Physics of Solids 1969;17(3):201-217.

[11] Budiansky, B., Hutchinson, J.W., Slutsky, S.. Void growth and collapse in viscous solids. Pergamon Press, Oxford; 1982, p. 13-45.

[12] Duva, J.M., Hutchinson, J.W.. Constitutive potentials for dilutely voided nonlinear materials. Mechanics of Materials $1984 ; 3(1): 41-54$.

[13] Zhang, X.X., Cui, Z.S.. Theoretical study of void closure in nonlinear plastic materials. Applied Mathematics and Mechanics-english Edition 2009;30(5):631-642. doi: \bibinfo\{doi\}\{10.1007/s10483-009-0509-7\}.

[14] Gurson, A.L.. Continuum theory of ductile rupture by void nucleation and growth: Part 1 - yield criteria and flow rules for porous ductile media. Journal of Engineering Materials and Technology, Transactions of the ASME 1977;99 Ser $\mathrm{H}(1): 2-15$.

[15] Faleskog, J., Gao, X., Shih, C.. Cell model for nonlinear fracture analysis - I. Micromechanics calibration. International Journal of Fracture 1998;89(4):355-373.

[16] Lassance, D., Fabregue, D., Delannay, F., Pardoen, T.. Micromechanics of room and high temperature fracture in 6xxx al alloys. Progress in materials science $2007 ; 52(1): 62-129$.

[17] Barsoum, I., Faleskog, J.. Rupture mechanisms in combined tension and shear-micromechanics. International Journal of Solids and Structures 2007;44(17):5481-5498.

[18] Bai, Y., Wierzbicki, T.. A new model of metal plasticity and fracture with pressure and lode dependence. International Journal of Plasticity 2008;24(6):1071-1096.

[19] Benzerga, A., Leblond, J.B.. Ductile fracture by void growth to coalescence. Advances in Applied Mechanics 2010;44:169305.

[20] Tomlison, A., Met, A., Dstringer, J.. La suppression des cavites internes dans les pieces de forge par refoulement. Journal of the Iron and Steel Institute 1958;:209-218.

[21] Keife, H., Ståhlberg, U.. Influence of pressure on the closure of voids during plastic deformation. Journal of Mechanical Working Technology 1980;4(2):133-143.

[22] Zutang, W., Meng, R.. Researches on the mechanisms of consolidating big steel ingots and optimization of forming procedure of large forgings. 12th International Forgemasters Meeting Conference; 1994.

[23] Chen, D.C.. Rigid-plastic finite element analysis of plastic deformation of porous metal sheets containing internal void defects. Journal of Materials Processing Technology 2006;180(1-3):193-200. doi: \bibinfo $\{$ doi $\}\{10.1016 / j . j m a t p r o t e c .2006$. $06.004\}$.

[24] Chun, M.S., Van Tyne, C.J., Moon, Y.H.. FEM analysis of void closure behaviour during open die forging of rectangular billets. Steel Research International 2006;77(2):116-121. 
[25] Chen, J., Chandrashekhara, K., Mahimkar, C., Lekakh, S.N., Richards, V.L.. Void closure prediction in cold rolling using finite element analysis and neural network. Journal of Materials Processing Technology 2011;211(2):245-255. doi: $\backslash$ bibinfo\{doi\} \{DOI:10.1016/j.jmatprotec.2010.09.016\}.

[26] Llanos, J.M., Santisteban, V., Demurger, J., Kieber, B., Forrestier, R., Rogberg, B., et al. Improvement of central soundness in long products from a through process control of solidification and reheating and rolling parameters. Tech. Rep.; European Commission - Research Fund for Coal and Steel; 2008. EUR 23588 EN.

[27] Park, C.Y., Yang, D.Y.. A study of void crushing in large forgings II. Estimation of bonding efficiency by finite-element analysis. Journal of Materials Processing Technology 1997;72(1):32-41.

[28] Shah, K.N., Kiefer, B.V., Gavigan, J.J.. Finite element simulation of internal void closure in open-die press forging. Advanced manufacturing processes 1986;1(3-4):501-516.

[29] Kim, P.H., Chun, M.S., Yi, J.J., Moon, Y.H.. Pass schedule algorithms for hot open die forging. Journal of Materials Processing Technology 2002;130-131:516-523.

[30] Ståhlberg, U.. Influence of spread and stress on the closure of a central longitudinal hole in the hot rolling of steel. Journal of Mechanical Working Technology 1986;13(1):65-81.

[31] Ståhlberg, U., Keife, H.. A study of hole closure in hot rolling as influenced by forced cooling. Journal of Materials Processing Technology 1992;30(1):131 - 135. doi: bibinfo\{doi\}\{10.1016/0924-0136(92)90043-R\}.

[32] Pietrzyk, M., Kawalla, R., Pircher, H.. Simulation of the behaviour of voids in steel plates during hot rolling. Steel Research 1995;66(12):526-529.

[33] Överstam, H., Jarl, M.. Fem-simulation of drawing out in open die forging. Steel Research International 2004;75(12):812817.

[34] Park, C.Y., Yang, D.Y.. Modelling of void crushing for large-ingot hot forging. Journal of Materials Processing Technology $1997 ; 67(1-3): 195-200$.

[35] Nakasaki, M., Takasu, I., Utsunomiya, H.. Application of hydrostatic integration parameter for free-forging and rolling. Journal of Materials Processing Technology 2006;177(1-3):521-524.

[36] Lee, Y.S., Kwon, Y.C., Kwon, Y.N., Lee, J.H., Lee, S.W., Kim, N.S.. Analysis on void closure behavior during hot open die forging. Advanced Materials Research 2007;24-25:69-72.

[37] Chen, K., Yang, Y., Liu, K., Shao, G.. Simulation of void defect evolvement during the forging of steel ingot. Advanced Materials Research 2010;97-101:3079-3084.

[38] Agouti, S.. Étude de l'origine de défauts détectés dans des pièces en alliage d'aluminium de la série 7xxx destinées à l'industrie aéronautique. Ph.D. thesis; École nationale supérieure des Mines de Paris; 2012. (in French).

[39] Wang, A., Thomson, P.F., Hodgson, P.D.. A study of pore closure and welding in hot rolling process. Journal of Materials Processing Technology 1996;60(1-4):95-102.

[40] Toda, H., Minami, K., Koyama, K., Ichitani, K., Kobayashi, M., Uesugi, K., et al. Healing behavior of preexisting hydrogen micropores in aluminum alloys during plastic deformation. Acta Materialia 2009;57(15):4391-4403.

[41] Chen, M.S., Lin, Y.. Numerical simulation and experimental verification of void evolution inside large forgings during hot working. International Journal of Plasticity 2013;49:53 - 70 .

[42] FORGE, . 2011 ${ }^{\circledR}$. Transvalor S.A.; 694, av. Donat, 06255 Mougins Cedex, France; 2011.

[43] Lasne, P.. Calculs supplémentaires : Présence de porosité; 2008. Internal document, unpublished.

[44] Zhang, X.X., Cui, Z.S., Chen, W., Li, Y.. A criterion for void closure in large ingots during hot forging. Journal of Materials Processing Technology 2009;209(4):1950-1959.

[45] Huang, Z.P., Wang, J.. Nonlinear mechanics of solids containing isolated voids. Applied Mechanics Reviews 2006;59(4):210-229. doi: \bibinfo $\{$ doi $\}\{10.1115 / 1.2192812\}$.

[46] Tvergaard, V.. On localization in ductile materials containing spherical voids. International Journal of Fracture $1982 ; 18(4): 237-252$.

[47] Tvergaard, V., Needleman, A.. Analysis of the cup-cone fracture in a round tensile bar. Acta Metallurgica 1984;32(1):157169.

[48] Scheyvaerts, F., Onck, P., Tekoglu, C., Pardoen, T.. The growth and coalescence of ellipsoidal voids in plane strain under combined shear and tension. Journal of the Mechanics and Physics of Solids 2011;59(2):373-397.

[49] Madou, K., Leblond, J.B.. A Gurson-type criterion for porous ductile solids containing arbitrary ellipsoidal voids-I: Limit-analysis of some representative cell. Journal of the Mechanics and Physics of Solids 2012;60(5):1020-1036.

[50] Madou, K., Leblond, J.B.. A Gurson-type criterion for porous ductile solids containing arbitrary ellipsoidal voids-II: Determination of yield criterion parameters. Journal of the Mechanics and Physics of Solids 2012;60(5):1037-1058.

[51] Ragab, A.R.. Application of an extended void growth model with strain hardening and void shape evolution to ductile fracture under axisymmetric tension. Engineering Fracture Mechanics 2004;71(11):1515-1534.

[52] Tvergaard, V.. On the creep constrained diffusive cavitation of grain boundary facets. Journal of the Mechanics and Physics of Solids 1984;32(5):373-393.

[53] He, M.Y., Hutchinson, J.W.. The penny-shaped crack and the plane strain crack in an infinite body of power-law material. Journal of Applied Mechanics 1981;48:830-840.

[54] Lee, B.J., Mear, M.E.. Axisymmetric deformation of power-law solids containing a dilute concentration of aligned spheroidal voids. Journal of the Mechanics and Physics of Solids 1992;40(8):1805-1836.

[55] Lee, B.J., Mear, M.E.. Studies of the growth and collapse of voids in viscous solids. Journal of Engineering Materials and Technology, Transactions of the ASME 1994;116(3):348-358.

[56] Ponte Castañeda, P.. The effective mechanical properties of nonlinear isotropic composites. Journal of the Mechanics and Physics of Solids 1991;39(1):45-71.

[57] Zhang, X., Ma, F., Ma, K., Li, X.. Multi-scale analysis of void closure for heavy ingot hot forging. Modern Applied 
Science 2012;6(10):15-25.

[58] Saby, M.. Understanding and modeling of void closure mechanisms in hot metal forming processes. Ph.D. thesis; Ecole Nationale Supérieure des Mines de Paris; 2013.

[59] Saby, M., Bernacki, M., Roux, E., Bouchard, P.O.. Three-dimensional analysis of real void closure at the mesoscale during hot metal forming processes. Computational Materials Science 2013;77:194-201. doi: $\backslash$ bibinfo $\{$ doi $\}\{10.1016 /$ j.commatsci.2013.05.002\}.

[60] Danas, K., Ponte Castañeda, P.. Influence of the Lode parameter and the stress triaxiality on the failure of elasto-plastic porous materials. International Journal of Solids and Structures 2012;49(11):1325-1342.

[61] Hutchinson, J., Tvergaard, V.. Comment on "Influence of the Lode parameter and the stress triaxiality on the failure of elasto-plastic porous materials" by K. Danas and P. Ponte Castañeda. International Journal of Solids and Structures $2012 ; 49(23): 3484-3485$.

[62] Cao, T.S., Gachet, J.M., Montmitonnet, P., Bouchard, P.O.. A Lode-dependent enhanced Lemaitre model for ductile fracture prediction at low stress triaxiality. accepted for publication in Engineering Fracture Mechanics 2014. 